7. Dejucq N, Jégou B. Viruses in the mammalian male genital tract and their effects on the reproductive system. Microbiol mol Biol Rev. 2001;65:208-31. http://dx.doi.org/10.1128/ MMBR.65.2.208-231.2001

8. Mansuy JM, Suberbielle E, Chapuy-Regaud S, Mengelle C, Bujan L, Marchou B, et al. Zika virus in semen and spermatozoa. Lancet Infect Dis. 2016;16:1106-7. http://dx.doi.org/10.1016/ S1473-3099(16)30336-X

9. Pillai SK, Good B, Pond SK, Wong JK, Strain MC, Richman DD, et al. Semen-specific genetic characteristics of human immunodeficiency virus type 1 env. J Virol. 2005;79:1734-42. http://dx.doi.org/10.1128/JVI.79.3.1734-1742.2005

Address for correspondence: Alex Paddy Salam, Epidemic Diseases Research Group, University of Oxford, Wellcome Trust Centre for Human Genetics, Roosevelt Drive, Oxford OX3 7BN, UK; email: alexsalam@doctors.org.uk

\section{Legionella pneumophila Serogroup 1 in the Water Facilitites of a Tertiary Healthcare Center, India}

\section{Rama Chaudhry, K. Sreenath, Valavane Arvind, E.V. Vinayaraj, Sagar Tanu}

Author affiliation: All India Institute of Medical Sciences,

New Delhi, India

DOI: https://doi.org/10.3201/eid2311.171071

Proactive environmental surveillance for Legionella pneumophila in hospitals that treat immunocompromised patients is a useful strategy for preventing nosocomial Legionnaires' disease. We report the presence of $L$. pneumophila serogroup 1 in $15.2 \%$ of the water systems of our tertiary healthcare center, which should prompt health officials to formulate mitigation policies.

$L$ egionella pneumophila, the causative agent of Legionnaires' disease (LD), is a bacterium omnipresent in aquatic environments and increasingly recognized as a major cause of community- and hospital-acquired pneumonia. L. pneumophila serogroup 1 ( $L p 1)$, the dominant serogroup, accounts for $\approx 84 \%$ of human infections worldwide $(1,2)$. Hospital-acquired LD has been reported globally, and routine use of environmental cultures is recommended as a useful strategy to prevent infections (3). Although proactive environmental surveillance of Legionella and regular treatment of cooling tower installations are recommended in many countries, these practices are not routine in India, and limited studies have been conducted in this country for monitoring Legionella contamination in hospital water systems (4). We conducted a study to detect L. pneumophila and to identify $L p 1$ in the water systems of a tertiary healthcare center in northern India that has organ transplantation and cancer treatment facilities.

We collected 79 water samples (41 potable, 38 nonpotable) from the hospital and general areas of the healthcare center during an 18-month period (May 2015-October 2016). Of 79 samples, 27 were collected from patient areas (wards, intensive care units, outpatient departments, emergency units, and procedure rooms); 14 from residential areas; 15 from cooling towers; and 23 from other buildings (e.g., laboratory divisions, teaching departments, library, and recreational zones). We followed guidelines issued by the US Centers for Disease Control and Prevention regarding isolation of Legionella (5). In brief, we concentrated $500 \mathrm{~mL}$ of water samples and decontaminated 1 part by using heat treatment (in water bath at $50^{\circ} \mathrm{C}$ for $30 \mathrm{~min}$ ) and 1 part by acid (in equal volume of $\mathrm{HCl}-\mathrm{KCl}$ acid buffer [ $\mathrm{pH}$ 2.2]). We then inoculated 0.1-mL samples onto buffered charcoal yeast extract agar (Becton Dickinson, Sparks, MD, USA) supplemented with glycine, vancomycin, polymyxin B, and cycloheximide (Oxoid, Basingstoke, UK). We presumptively identified colonies growing only on buffered charcoal yeast extract but not on blood agar as Legionella species and confirmed the presence of L. pneumophila by amplification of a 375-bp region of the mip gene using previously published primers (6). We identified $L p 1$ by using a real-time PCR (rPCR) assay targeting the wzm gene (7). We used genomic DNA isolated from $L$. pneumophila strain Philadelphia (ATCC 33152) for standardization of PCR and rPCR and L. pneumophila strain Knoxville (ATCC 33153) for standardization of culture.

We identified Legionella spp. in 21 (26.6\%) of 79 water samples (10 potable and 11 nonpotable) by culture. We obtained a collection of 28 isolates from the 79 samples and identified all of them as L. pneumophila by PCR. Among these 28 isolates, 18 (64.3\%) tested positive for $L p 1$ by $\mathrm{rPCR}$, indicating the presence of this pathogenic serogroup in $12(15.2 \%)$ of the 79 water samples (5 potable and 7 nonpotable).

We repeatedly isolated L. pneumophila ( $>4$ times) from 2 high-risk sites: a drinking water unit and a cooling tower situated inside the hospital campus. Four water samples collected from patient areas tested positive for L. pneumophila, posing a risk for nosocomial infection. We isolated L. pneumophila from water bodies with temperatures ranging from $12^{\circ} \mathrm{C}$ to $57^{\circ} \mathrm{C}$ but most frequently (11 times) from those with temperatures of $25^{\circ} \mathrm{C}-50^{\circ} \mathrm{C}$. We summarized the isolation of $L$. pneumophila with 
respect to type of water sample, sampling site, and temperature (Table).

We demonstrated the presence of $L p 1$ in the hospital water systems, indicating that LD might be a common cause of pneumonia in this setting. Previously published reports have documented infections attributable to L. pneumophila in patients with community-acquired pneumonia; however, the prevalence of nosocomial legionellosis in India remains unknown $(4,8,9)$.

On the basis of our findings, we initiated infection control measures and created awareness to formulate $L e$ gionella risk management in this hospital. We ensured that physicians were cognizant of possible Legionella colonization in the hospital water supply and advised them to recommend Legionella diagnostic testing for patients with suspected nosocomial pneumonia. Underdiagnosed nosocomial legionellosis might become evident as the awareness of clinicians increases and as specialized laboratory testing for the pathogen becomes easily available.

Eradication of Legionella from aquatic bodies is a herculean task. Numerous systemic disinfection measures are available, such as super heat and flush, copper-silver ionization, chlorine dioxide, and point-of-use filters, but no method is ideal for complete eradication of the contagion (10). We advised the hospital's engineers and healthcare facility managers to install point-of-use filters to the drinking water taps in areas where Legionella was isolated. Repeat sampling of 2 sites that had once tested positive for Legionella showed that they were culture-negative for the pathogen 6 six months after installation of the filters. However, to evaluate the efficacy of any disinfection method, validation and monitoring over a prolonged period is required.

Our findings might be an important sentinel of an underestimated threat and could be useful for health officials in India to set standards for LD surveillance and control in hospitals. Although we did not perform sequence-based typing in this study, examination of

\begin{tabular}{|c|c|c|}
\hline Characteristic & $\begin{array}{c}\text { Samples positive } \\
\text { for } L \text {. pneumophila, } \\
n=21\end{array}$ & $\begin{array}{l}\text { Samples positive for } \\
\text { L. pneumophila } \\
\text { serogroup } 1, \mathrm{n}=12\end{array}$ \\
\hline \multicolumn{3}{|l|}{ Type of water } \\
\hline Potable & 10 & 5 \\
\hline Nonpotable & 11 & 7 \\
\hline \multicolumn{3}{|l|}{ Sampling site } \\
\hline Patient area & 4 & 3 \\
\hline Residential area & 6 & 1 \\
\hline Cooling tower & 5 & 3 \\
\hline Other building & 6 & 5 \\
\hline \multicolumn{3}{|l|}{ Temperature, ${ }^{\circ} \mathrm{C}$} \\
\hline$<25$ & 9 & 4 \\
\hline $25-50$ & 11 & 7 \\
\hline$>50$ & 1 & 1 \\
\hline
\end{tabular}

Legionella from natural sources and advances in molecular typing might help clarify the distribution and natural history of LD in this region.

\section{Acknowledgments}

The authors acknowledge Arti Kapil, Bijay Ranjan Mirdha, Benu Dhawan, and Urvashi B. Singh for their valuable suggestions and inputs. We also thank Mohanlal Sharma, Puran Ram, and Pramod Kumar for their technical support.

Dr. Chaudhry is professor of microbiology at All India Institute of Medical Sciences, New Delhi, India, and American Society for Microbiology international ambassador to India. Her research focuses on atypical pneumonia, vectorborne diseases, anaerobic infections, probiotics, and metagenomics.

\section{References}

1. Fields BS, Benson RF, Besser RE. Legionella and Legionnaires' disease: 25 years of investigation. Clin Microbiol Rev. 2002; 15:506-26. http://dx.doi.org/10.1128/CMR.15.3.506-526.2002

2. Mercante JW, Winchell JM. Current and emerging Legionella diagnostics for laboratory and outbreak investigations. Clin Microbiol Rev. 2015;28:95-133. http://dx.doi.org/10.1128/CMR.00029-14

3. Sabria M, Yu VL. Hospital-acquired legionellosis: solutions for a preventable infection. Lancet Infect Dis. 2002;2:368-73. http://dx.doi.org/10.1016/S1473-3099(02)00291-8

4. Anbumani S, Gururajkumar A, Chaudhury A. Isolation of Legionella pneumophila from clinical and environmental sources in a tertiary care hospital. Indian J Med Res. 2010;131:761-4.

5. Centers for Disease Control and Prevention. Procedures for the recovery of Legionella from the environment. Atlanta: US Department of Health and Human Services, Public Health Service; 2005. p. 1-13.

6. Welti M, Jaton K, Altwegg M, Sahli R, Wenger A, Bille J. Development of a multiplex real-time quantitative PCR assay to detect Chlamydia pneumoniae, Legionella pneumophila and Mycoplasma pneumoniae in respiratory tract secretions. Diagn Microbiol Infect Dis. 2003;45:85-95. http://dx.doi.org/10.1016/ S0732-8893(02)00484-4

7 Benitez AJ, Winchell JM. Clinical application of a multiplex real-time PCR assay for simultaneous detection of Legionella species, Legionella pneumophila, and Legionella pneumophila serogroup 1. J Clin Microbiol. 2013;51:348-51. http://dx.doi.org/ 10.1128/JCM.02510-12

8. Chaudhry R, Valavane A, Mohan A, Dey AB. Legionella pneumophila infection associated with renal failure causing fatality in a known case of sarcoidosis. Indian J Med Microbiol. 2014;32:324-7. http://dx.doi.org/10.4103/0255-0857.136590

9. Angrup A, Chaudhry R, Sharma S, Valavane A, Passi K, Padmaja K, et al. Application of real-time quantitative polymerase chain reaction assay to detect Legionella pneumophila in patients of community-acquired pneumonia in a tertiary care hospital. Indian J Med Microbiol. 2016;34:539-43. http://dx.doi.org/ 10.4103/0255-0857.195353

10. Lin YE, Stout JE, Yu VL. Controlling Legionella in hospital drinking water: an evidence-based review of disinfection methods. Infect Control Hosp Epidemiol. 2011;32:166-73. http://dx.doi.org/10.1086/657934

Address for correspondence: Rama Chaudhry, Department of Microbiology, All India Institute of Medical Sciences, Ansari Nagar, New Delhi 110029, India; email: drramach@gmail.com 